\title{
Reference from a Behaviorist Point of View
}

\author{
Don Howard \\ Department of Philosophy and \\ History and Philosophy of Science Graduate Program \\ University of Notre Dame
}

\section{Introduction: The Semantic Naturalism of Dewey and Quine}

With good reason, the "linguistic turn" or "semantic turn" is regarded as one of the enduring achievements of later-nineteenth and early-twentieth century philosophy. Judgments are not to be confused with propositions, and philosophical questions about the relation between language and world are to be disentangled from psychological questions about the workings of the mind and its causal connections to the world. The rise of modern analytic philosophy (and much of later continental philosophy as well) would have been impossible had it not been for the antipsychologistic revolution of the late-nineteenth century, which reshaped the philosophical problem space and reworked the geography of the disciplines, psychology and philosophy becoming separate departments in most universities, the former an empirical, experimental science, the latter not. ${ }^{1}$ It is ironic, however, that, at almost the same time, evolutionary naturalism became a prominent current, at least in North American philosophical thought, ${ }^{2}$ thinkers otherwise as diverse in philosophical orientation as John Dewey and Roy Wood Sellars seeking to embed epistemology, especially, in a broadly Darwinian setting. ${ }^{3}$ Evolutionary naturalism was somewhat less fashionable in the decades immediately after the Second World War, but by the 1970s it found a new audience, and evolutionary epistemology remains, today, a thriving area of research. ${ }^{4}$ In this version of naturalism, biology is the grounding science, but naturalists like Dewey, or W. V. O. Quine, to name a more recent exemplar (and one who acknowledges a major debt to Dewey), would also emphasize the 
continuities between biological and psychological perspectives on knowledge and language, psychology simply picking up the scientific story at that point in the life of the individual where evolutionary accounts of the species cease to be useful. For Dewey, that meant functional psychology; for Quine, it meant the Skinnerian version of behaviorism, or "operant theory."

For much of the twentieth century, these two traditions - analytic philosophy and evolutionary naturalism - lived in tension. In the Tractatus (1922), Ludwig Wittgenstein gave canonical expression to the idea that philosophy and empirical science, evolutionary biology in particular, have, as a matter of principle, nothing to do with one another. Wittgenstein wrote:

\subsection{Philosophy is not one of the natural sciences.}

and

4.1122 Darwin's theory has no more to do with philosophy than any other hypothesis in natural science.

Indeed, if philosophy is just conceptual or linguistic analysis, then empirical science is irrelevant to the philosopher's task.

Some thinkers, however, crossed the analytic/naturalistic divide, Quine being here, too, a prime exemplar. He argued, famously, that his behavioral perspective on language was subversive of the notions of meaning (sense) and reference that descended from Gottlob Frege (1892) and were central to analytic philosophy of language. ${ }^{6}$ If evidence in the form of verbal behavioral dispositions provides our only access to meaning, then the assignment of meanings to terms and propositions is underdetermined by the evidence. Reference is similarly underdetermined by the behavioral evidence and is, thereby, rendered "inscrutable."

One noteworthy response to Quine also crossed the analytic/naturalistic divide. Philosophers 
like Hilary Putnam (1970), Saul Kripke (1971, 1972), and Richard Boyd (1979) sought to render reference "scrutable" and determinate again by means of a causal theory of reference. ${ }^{7}$ The idea is that terms acquire a fixed reference, becoming a "rigid designator," by means of an initial act of "dubbing" or "baptism," as when a parent teaches a child the word "red" by pointing to a red ball, with all speakers' usages of the term being connected to this initial act by a causal process, as when the child tells a friend, the friend tells a neighbor, and so forth.

In what sense these processes are "causal" is puzzling, likewise in what sense the whole scheme is "naturalistic." A more fundamental question concerns how pointing alone can disambiguate reference in the absence of other verbal cues. Am I pointing to the ball's color, its shape, its size, its texture, its patterning? Deeper still is the question how, in principle, a causal relationship (read "physical," "biological," etc.) can have anything whatsoever to do with the semantic relationship of reference. One worries that some sort of category mistake has been committed here.

Reference understood in a purely formal sense, as a mapping from uninterpreted signs in a formal language to elements of a model, is untouched by many of the above-mentioned worries about Quinean referential inscrutability or the limitations of a causal theory of reference. ${ }^{8}$ The serious difficulties all accumulate around the notion of reference as applied to terms in natural languages, as these are spoken and used by real human speakers in the real (or even fictional or counterfactual) worlds. Should we be surprised? Alfred Tarski had already cautioned back in the 1930s that the semantics of natural language would be a messier business than the semantics of formal languages, if only because the notion of sentencehood - what counts as a well-formed formula - is not 
recursively specifiable for natural languages (Tarski 1935). That sentencehood is not recursively specifiable for natural languages reflects the distinctive plasticity of natural languages, the fact that natural languages are capable of not just an infinite novelty of form, but an infinite novelty of form that cannot be captured even by infinitely open-ended rules. Such a capacity for novelty is seen also in the referring expressions of natural languages.

The non-recursive plasticity of natural language is a point to which we shall return below. It is but one of various ways in which natural language - the language of poetry, song, and everyday human commerce, as well as the language of much of science and philosophy - eludes our efforts to capture language in formulas. Naturalists like Dewey and Quine appreciated this point, which is one reason why both turned from logic to behavioral psychology as affording more helpful scientific tools for understanding how natural language works.

One could be a psychological naturalist about language while taking the elements of language to be mental entities. But Dewey was emphatic on the point that language and meaning are matters of overt behavior, not the speaker's inner mental life. Dewey put it this way in Experience and Nature (using the term "meaning" in a broad way that comprehends both sense and reference):

Meaning is not indeed a psychic existence; it is primarily a property of behavior, and secondarily a property of objects. But the behavior of which it is a quality is a distinctive behavior; cooperative, in that response to another's act involves contemporaneous response to a thing as entering into the other's behavior, and this upon both sides. It is difficult to state the exact physiological mechanism involved. But about the fact there is no doubt. (Dewey $1925,179)$

Quine was very much of the same opinion. In his 1968 John Dewey lectures at Columbia he explained his debt to Dewey this way:

Philosophically I am bound to Dewey by the naturalism that dominated his last three decades. 
With Dewey I hold that knowledge, mind, and meaning are part of the same world that they have to do with, and that they are to be studied in the same empirical spirit that animates natural science.

When a naturalistic philosopher addresses himself to the philosophy of mind, he is apt to talk of language. Meanings are, first and foremost, meanings of language. Language is a social art which we all acquire on the evidence solely of other people's overt behavior under publicly recognizable circumstances. Meanings, therefore, those very models of mental entities, end up as grist for the behaviorist's mill. Dewey was explicit on the point: "Meaning ... is not a psychic existence; it is primarily a property of behavior." (Quine 1968, 185)

Note that Quine, like Dewey, takes the behavioral perspective on language and meaning also to imply the inherently social character of language. This is a point to which we shall return below when discussing Skinner's concept of verbal behavior.

But what does it mean to say that "meaning . . . is primarily a property of behavior? We do not ordinarily think of Dewey as a behaviorist. He was, famously, a proponent of the functionalist alternative to the structuralism that dominated American psychology in the late-nineteenth and earlytwentieth centuries, ${ }^{9}$ and he was a famous critic of early stimulus-response or reflex forms of behaviorism. In his classic paper, "The Reflex Arc Concept in Psychology," he argued that stimulus and response could not be seen as separate units of analysis, that they had to be regarded from the point of view of their functional relationship as a unitary whole (Dewey 1896). But, in fact, this functionalist conception of the relationship among stimulus, response, and, most importantly, the accumulated results of earlier experience anticipates the later Skinnerian version of behaviorism, known as "operant theory," for, as we shall see below, Skinner defines the operant as his fundamental unit of analysis in precisely this way, namely, as a three-term functional relationship among stimulus, response, and the history of contingencies of reinforcement.

It is unfortunate that Dewey never developed his behavioral perspective on meaning beyond 
the kind of programmatic remarks already quoted. The sophisticated notion of "habit" that is the basic unit of analysis of his psychology (see especially Dewey 1922) would have served as a useful resource for such a task.

Quine explicitly situated himself in the later behaviorist camp of his Harvard colleague, B. F. Skinner, and in works like Word \& Object (Quine 1960) and The Roots of Reference (Quine 1973) he explored in great detail the consequences for semantics of the adoption of a behavioral perspective on language. But even Quine disappoints by of the lack of theoretical sophistication in his behaviorism, his being little better than an armchair version of Skinnerian operant psychology. Thus, in the well-known argument for the indeterminacy of radical translation in Word \& Object, behaviorism lives only in the form of Quine's taking as evidential a native informant's verbal dispositions to assent or dissent when confronted by queried uses of native locution, as when the linguist queries “Gavagai?" on the occasion of his or her noticing a rabbit in the field of view (Quine 1963, 26-79). Worse still, in The Roots of Reference and other writings, Quine makes the fundamental mistake of assuming that stimulus conditions at receptor surfaces, what psychologists term "proximal" stimuli, are what stand in the relevant law-like relations to the verbal behavioral responses that are mainly of interest (Quine 1973). ${ }^{10}$ Only a little sophistication would have been required to understand that more relevant in most situations are what are known as "distal stimuli," which means, in effect, in many settings, ordinary, medium-sized physical objects. If one wants to understand why a subject vocalizes "chair," in the presence of the chair, then look to the chair and not the photons impinging on the retina. Most surprising of all, in Quine's version of semantic naturalism, is that, in spite of his invoking the authority of Skinner, he nowhere makes use of any 
of the theoretical apparatus developed in Skinner's own profound and detailed study of language, his 1957 book, Verbal Behavior (Skinner 1957). ${ }^{11}$

Like Dewey and Quine, I think that behavior is where meaning is made manifest. Like Quine, I think that a behavioral perspective on semantics is likely to yield results subversive of the notions of meaning and reference that have descended to us from Frege. But I also think that an important opportunity was lost when Quine and other semantic naturalists failed to make use of the sophisticated theoretical apparatus developed in Skinner's Verbal Behavior. That the opportunity was lost is, in some ways, not surprising. Even Quine's amateur behaviorism came under swift and strong attack from critics like Jerrold Katz and Jeffrey Fodor. ${ }^{12}$ By the late 1960s and early 1970s, the influence of Skinnerian operant theory was beginning to wane in the face of the cognitive revolution in psychology (see Neisser 1967). And, of course, Skinner's Verbal Behavior had, itself, been the target of what is remembered by many - wrongly, in my opinion - as a famously destructive review by Noam Chomsky (Chomsky 1959). ${ }^{13}$ Still, this was, I think, an opportunity lost, and my principal aim in the rest of this paper is to give a sketch of what a more sophisticated operant theory of meaning and reference would look like and to make clear the main ways in which it would constitute a dissent both from the Fregean tradition in semantics and from the other dominant forms of semantic naturalism, such as the causal theory of reference.

\section{An Outline of Skinnerian Operant Theory}

We begin with a primer on the basic ideas of Skinnerian operant theory before looking at how this framework is deployed by Skinner in the study of verbal behavior. Philosophers often learn 
about behaviorism by reading either Gilbert Ryle (1949) or Chomsky (1959). This is unfortunate, for, like casual readers of Skinner's own more popular work, philosophers thus fail to appreciate fully the nature and extent of the Skinnerian revolution in behavioral psychology.

The chief theoretical construct of early behaviorists, such as John B. Watson, was the concept of respondent behavior, more commonly designated as reflex behavior. ${ }^{14}$ Respondent behavior involves a two-term relationship between a feature of the environment, called the stimulus, and an activity of the organism, dubbed the response. The role of the stimulus was originally conceived as that of "eliciting" or "releasing" the response, but in laboratory situations, at least, where such metaphysics may safely be forsworn, one need only assume a functional relationship between the two. The stimulus is merely an occasioning event, one in the presence of which a response is more or less probable. Some stimulus-response associations are natural, such as a dog's salivating at the sight of food, whereas others can be established by conditioning, as Ivan Pavlov demonstrated by getting a dog to salivate also at the sound of a bell.

Examples of respondent behavior abound, both in nature and in the laboratory, and this fact encouraged early behaviorists to promote this simple stimulus-response (S-R) pattern as the model for all human behavior. With the advantage of hindsight, we now see clearly that there are serious and fundamental limitations of the respondent model, but our less advantaged predecessors saw only puzzles, to which they responded with a variety of ad hoc devices. Typical of the difficulties with the S-R model is the fact that stimuli that one would expect to be effective often fail to elicit any response whatsoever. More generally, one finds that a variety of responses can be conditioned to the same stimulus, and, that, conversely, a single response can be brought under the control of several 
different stimuli. None of these phenomena can be explained by a model that speaks only of stimulus and response; something more is needed. It was this situation that led behaviorists such as Edward C. Tolman and Clark Hull to posit "intervening variables" as hypothetical intermediaries whose function is to account for the failure of a neat one-to-one connection between stimuli and responses.

From a purely formal point of view, there can be no objection to posited intervening variables - they can be made to do the work expected of them. But from the point of view of the pragmatics of a developing experimental science of behavior there is much to criticize in a hasty flight to hypothesis. As Skinner noted, the "central states" that intervening variables are taken to represent invite interpretation as either mental states or neurological states, and once such an interpretation is made, central states take on a reality that is more a function of the familiarity of discourse about minds or neurons than of the concrete evidence for these specific posits. Inevitably, one's descriptions of central states borrow heavily from the vocabularies of other disciplines, such as neurophysiology, information theory, or more recently, computing theory and artificial intelligence. Skinner worried that one thus purchases a "spurious sense of order or rigor" at the expense of experimental control (Skinner 1969, 83).

Recourse to hypothetical intervening variables is especially unwise when the possibility exists of supplementing the basic S-R model with a more directly "observable" third term, and it is observability, or, more precisely, accessibility to experimental control, that is the chief distinguishing methodological virtue of Skinner's alternative to intervening variables: contingencies of reinforcement.

The concept of "contingencies" encapsulates an important feature of most behavior that had 
been neglected by many behavioral psychologists up to Skinner's time, namely, the effect that the consequences of present behavior have upon future behavior. In classical, respondent conditioning, reinforcement is provided regardless of the organism's response. Pavlov, for example, did not make the presentation of food contingent upon the dog's salivating; he simply rang the bell and presented the food. In operant conditioning, on the other hand, reinforcement is forthcoming only when a specific kind of response occurs; the rat is fed only when it presses the bar within a suitable length of time after the stimulus is presented.

There is nothing hypothetical about contingencies, especially in well-controlled laboratory situations. The consequences of an experimental organism's behavior are easily inferred from the design of the experimental apparatus. Moreover, the concept of contingencies can, in principle, be called upon to deal with most or all of the problems that the concept of intervening variables was invented to solve. ${ }^{15}$

In outline, the model that Skinner proposes is that of the operant: a three-term functional relationship among stimulus, response, and contingencies of reinforcement. In operant behavior, the probability of an organism's emitting a given response when exposed to a specific stimulus (as measured by the organism's rate of responding in the presence of that stimulus) is primarily a function of the contingencies of reinforcement to which the organism has been subjected. ${ }^{16}$ The fact that an operant is a three-term functional relationship has important consequences, for it implies that the identity conditions for operants are not simply those of the component responses. Instead, operants are individuated on the basis of patterns of functional dependence; an operant is not just a response, but a way of responding. Various facile criticisms of Skinner fail precisely because of their 
neglect of this elementary point, and Skinner's insistence on the functional nature of the relationship constitutive of the operant betrays his debt to the functionalism that Dewey and his students defended a generation earlier.

Over seventy years have passed since the introduction of the operant concept (Skinner 1938), and during that time an abundance of data has been accumulated on the specific ways in which probability of response depends upon different schedules of reinforcement. Many of the regularities discovered have been found to be independent of the nature of the stimulus, the response, the reinforcer and even the experimental organism. That fact, together with the success of Skinner and his students in explaining, by means of the operant model, a wide variety of sometimes very complex behaviors, is good reason to continue to promote operant analysis at least as a program for research in psychology. This is not to assert, dogmatically, that operant psychology is the last word in the investigation of human behavior, and, clearly, it is not widely regarded as such today. The point is, instead, to suggest that research according to the operant paradigm has paid and promises to continue paying dividends, and that the shortcomings of the operant model are more likely to be discovered through a concerted effort to extend an operant analysis to ever more complex kinds of behavior, than through a critique based upon intuitions about the existence of intentional or mental entities.

\section{Skinner on Verbal Behavior}

Research has shown that operants fall into definite classes defined by the nature of the relationship among stimulus, response, and contingencies of reinforcement. The most important class for the purposes of a behavioral semantics is that of verbal behavior, which Skinner defines as 
"behavior reinforced through the mediation of other persons" (Skinner 1957, 2). An example illustrating the crucial property of mediation in a clear form would be a child's acquisition of the verbal operant Water $!^{17}$ In an appropriately contrived environment, a child might learn to crawl to a dish of water when he or she is thirsty; this would be non-verbal operant behavior, because the response, the crawling, leads directly to the reinforcement. More commonly the child learns to emit a certain vocal response, which, if heard by another member of the verbal community, frequently leads to reinforcement. This is genuine verbal behavior, because the reinforcement is contingent upon the response's being, itself, a stimulus for an item of (often non-verbal) behavior by another individual; the latter's response is what reinforces the former's vocal response.

The broad class of verbal operants is subdivided into a number of more specific kinds of operants. Mands are exemplified by the child's asking for water. The mand is distinguished, to quote Skinner, "by the unique relationship between the form of the response and the reinforcement characteristically received in a given verbal community" (Skinner 1957, 36). To put it crudely, the response "specifies" its reinforcement. Mands are further distinguished by the fact that no specific stimulus condition is required, except, perhaps, a certain state of deprivation and the presence of an appropriate audience. However, several verbal operants do require a specific kind of stimulus. Some require a specifically verbal stimulus, as suggested by the names Skinner gives them, such as "echoic behavior," "textual behavior," "transcription," and "intraverbal behavior" (Skinner 1957, Ch. 4).

The members of one important class of operants, the tacts, do require, however, a non-verbal stimulus. This is the kind of verbal behavior most relevant to a behavioral semantics, because the relationship between response and stimulus in a tact resembles, in some respects, the relationship 
between a word and its referent. In fact, there is an important difference between tacting and referring, a difference that hints at the larger difference between the study of language and the study of verbal behavior: reference is a two-term relationship between word and object; but the tact, like other operants, is a three-term relationship among response, stimulus, and contingencies of reinforcement. Beyond its requiring a non-verbal stimulus, what distinguishes the tact from other verbal operants is the strength of the control exerted by the prior stimulus - no specific deprivation, audience, or aversive stimulation is required, a situation produced by the community's reinforcing the response in question in a wide variety of circumstances, using an assortment of reinforcers, the only common factor being the presence of the appropriate non-verbal stimulus (Skinner 1957, Ch. 5). Examples abound: Dog consistently reinforced in the presence of a dog; red consistently reinforced in the presence of red things; and so on.

Given the tact's proximity to the traditional semantic notion of reference, we will want to investigate more carefully what Skinner has to say about this class of operants. But pause, first, to think about some of the important, distinguishing features of Skinner's conception of verbal behavior. First, verbal behavior is not different in kind from other operant behavior, except for its unique, socially mediated mode of reinforcement. The fact that verbal and non-verbal behaviors are thus similar in kind suggests that a Skinnerian behavioral semantics might not have to face a problem that is a continuing source of embarrassment to more traditional philosophies of language, namely, the problem of the relation between language and action. For Skinner, there is no difference in kind between verbal behavior and other behavior. The only possible differences are those that can be characterized in terms of the pattern of functional relationships among stimulus, response, and 
contingencies of reinforcement.

Second, verbal behavior is defined in an extremely general way, so as to include a wide variety of non-vocal and yet verbal behaviors, some of which we might not intuitively assimilate to language. Any kind of response that is established and maintained by socially mediated reinforcement qualifies as verbal. Among the non-vocal verbal behaviors will be included, of course, writing, typing, signing, pointing, and other forms of signaling, such as Morse code and semaphore, also gesturing, like waving hello and goodbye, indicating assent with a wink and a nod, and so forth. Perhaps more surprising will be the inclusion of behaviors that one might have thought not to be in any way verbal, such as musical, artistic, and athletic performance or a craft person's physical manipulation of wood, clay, or paint. To the extent that the reinforcement of Michael Jordan's slam dunk or John Coltrane's improvisation is social, to that extent the behavior is verbal. We often describe athletics, art, and music as forms of expression, even though there might be no obvious semantic content expressed, so we say, with less than full conviction, that what they express must be something like emotional attitudes. But there are no such puzzles from the operant point of view. Such behaviors are expressive in the same way as are other verbal behaviors. Even further removed from intuitions about language might be such examples as the socially mediated reinforcement of the apprentice laboratory assistant's handling of experimental equipment. What it is that might be communicated in training an apprentice is as puzzling as is the expressed content of music or athletic performance. Perhaps, in desperation, we speak of tacit knowledge. But here, too, recognition of the crucial role of social mediation in reinforcement makes clear the continuity with other verbal behavior. Learning to speak and learning to titrate do have a lot in common. 
Especially interesting among the class of non-vocal verbal behaviors is what Skinner terms "sub-vocal" verbal behavior, which comprises everything from talking to oneself to what some might term "the language of thought." How language shapes "thinking" is a famous problem in psychology. ${ }^{18}$ Make language and thought different in kind and you make the problem a hard one. Make thought just a species of sub-vocal verbal behavior and you make the problem much easier to solve. The point is not that all cognition is just interiorized verbal behavior. That is, obviously, false. The point is just that much of what we term "thinking" is like in kind - in operant terms - to verbal behavior in other forms, even if the responses are non-vocal. What is crucial is, again, the socially mediated way in which those habits of responding are established and maintained.

Finally, from an operant point of view, verbal behavior is, as already emphasized, necessarily social behavior. The distinctively verbal pattern of relations among stimulus, response, and reinforcement is displayed only by an organism that is a member of a verbal community, that is, a group of organisms some of whose behavior is reinforced not by the natural environment, but by the responses of other members of the group. It follows that there can be no private verbal behavior. This does not rule out verbal behavior under the control of internal stimuli, which previously we would have termed "talk about private events"; it merely implies that such verbal behavior, like all verbal behavior, is shaped and maintained by socially mediated reinforcement.

\section{Tacting as a Surrogate for Referring}

As mentioned, the class of verbal operants that Skinner labels "tacts" affords us the closest behavioral analogue of the semantic notion of reference, this because of the tact's distinguishing 
characteristic, namely, the control exerted by a prior, non-verbal stimulus. Skinner, himself, says of the tact: "The resulting control is through the stimulus. A given response 'specifies' a given stimulus property. This is the 'reference' of semantic theory" (Skinner 1957, 85). Skinner is not, however, proposing here a behavioral explication of the traditional semantic notion of reference. The referential relationship between a dog and the term "dog" might be thought to resemble the functional relationship between a dog and the vocal response, $\operatorname{dog}$. But, from a behavioral point of view, there are crucial differences, for a term or a word is not at all the same thing as a vocal response, and essential to the tact as a verbal operant is that third term, the history of contingencies of reinforcement - something with no analogue in the reference relationship - for the details of that history are precisely what produces the distinctively strong stimulus control in the tact.

Consider each of these two points of difference in turn. A word or term is not a vocal response. A word or term is an abstract object. A vocal response is a concrete, physiological and physical event. One might think to define a word, behaviorally, as an equivalence or similarity class of utterances and inscriptions not only across a big chunk of the biography of a single individual but also across the careers of all members of a relevant verbal community. A word defined thus as an abstract object might be capable of standing in a reference-like relationship to an object as its referent, and it might even play by the rules of formal syntax and inference. But there is no a priori reason to expect the semantic reference relationship - essentially just a mapping - to supervene upon or reduce to the functional relationship between stimulus and response in the corresponding tact. Nor is there any a priori reason to expect, conversely, that that functional relationship in the tact should track the reference relationship. 
The second difference is more important. The tact is a three-term functional relationship among stimulus, response, and contingencies of reinforcement, and such a third term is lacking in the semantic relationship of reference. For Skinner, it is the operant, in this case the tact, that is the proper unit of analysis, not the response alone, even less so the word. The mistake of taking the response or the word as the proper unit of analysis is labeled the "formalistic fallacy" by Skinner, who remarks that it is "common in linguistics and psycholinguistics" and that it is "most damaging when verbal behavior is analyzed as if it were generated through the application of rules" (Skinner 1969, 89-90). It is a mistake precisely because it directs attention away from the crucial controlling variables in verbal behavior, foremost among them the contingencies of reinforcement.

There is special irony in neglecting the controlling variables in the case of tacting as a behavioral surrogate for reference, since, as noted, it is precisely the contingencies of reinforcement that establish the characteristically strong stimulus control in the tact, the feature of the tact that makes it seem so much like reference. Such strong stimulus control is established by contingencies that reinforce the relevant response $-d o g-$ in the presence of a discriminative stimulus - a dog over a wide range of background conditions and in the absence of any specific deprivation or aversive stimulation. Change those contingencies and the topographically identical response can be part of an entirely different verbal operant, such as a mand.

Skinner devotes a long section of Verbal Behavior to what he terms "The problem of Reference" (Skinner 1957, 114-129). He stresses that the tact of operant theory is not an explication of the semantic notion of reference but a replacement for it: "We are interested in finding terms, not to take traditional places, but to deal with a traditional subject matter" (115). How are we to "deal 
with" this traditional subject matter? Skinner explains:

Semantic theory is often confined to the relation between response and stimulus which prevails in the verbal operant called the tact. Words, parts of words, or groups of words on the one hand and things, parts of things, or groups of things on the other stand in a relation to one another called "reference," "denotation," or "designation." The relation may be as empty as a logical convention or it may provide for the "intention" of the speaker. But how a word "stands for" a thing or "means" what the speaker intends to say or "communicates" some condition of a thing to a listener has never been satisfactorily established. The notion of the verbal operant brings such relations within the scope of natural science. (114-115)

Skinner surveys several noteworthy ways in which the operant surrogate for reference redirects our understanding of the relation between language and meaning or verbal behavior and world. One concerns the reference of general and abstract terms. One might think this a problem in a behavioral analysis, since reinforcement always takes place in the presence of specific, concrete objects. But what is required is simply that one systematically vary stimulus properties noting those in which a specific response is present or absent. What do we find?

We cannot solve this problem by giving the relevant property a sort of object-status as a "concept" or "abstraction"-by saying that the response red refers to the "concept of red" or to the "redness" of something. We never reinforce a response when a "concept" is present; what is present is a particular stimulus. The referent of an abstract tact, if this term has any meaning at all, is the property or set of properties upon which reinforcement has been contingent and which therefore control the response. We might say that the referent is the class of stimuli defined by such a property or properties, but there is little reason to prefer classes to properties. The property correlated with reinforcement must be specified, in physical terms, if we are to remain within the framework of empirical science. (117)

The class of stimuli or the properties thus identified behaviorally as the referent of an abstract term will depend upon the details of the reinforcing practices of the relevant verbal community and might not correspond closely to the philosopher's pre-analytic intuitions about natural kinds. Stay with color terms. One can imagine verbal communities wherein the contingencies of reinforcement depend more strongly upon intensity than wavelength, just as one can imagine a community in 
which, thanks to accidents of plumage among birds that are targets of prey, it is functional to reinforce a single response to colors as different, to us, as red is from purple.

Concrete but general terms might seem to pose fewer puzzles. But here, too, the lesson stands that responses are reinforced always in the presence of particular stimuli. "Where the stimulus appears to be an object, the object is taken is as the referent of the response; yet there is always an element of abstraction. We cannot point to a single chair which is the referent of the response chair" (117) From a behavioral point of view, there is a continuum of cases running from proper names to abstract terms, the various tacts differing only in the degree of stimulus generalization involved.

It is a matter of special importance to Skinner that a single response can be under the control of different stimuli, and that a single stimulus can control a multiplicity of responses. Both cases afford a continuum of possibilities. A single response under the control of similar stimuli corresponds to either abstraction or metaphor depending upon how we regard the dimensions along which the stimuli vary. Both begin as examples of what Skinner terms "extension," which is characterized by a response's being emitted in the presence of stimuli before which the response had not previously been reinforced. Abstraction is a matter of "generic extension," the variety of extension in which the property making the stimulus effective is that upon which the community's reinforcement was contingent, as when a subject vocalizes chair when confronted by a new kind of chair. "Metaphorical extension," in Skinner's parlance, occurs when the effective property of the stimulus is one that happened to have been present when the response was reinforced but was not among the properties respected by the verbal community's contingencies. Skinner gives the example of a child who, when drinking soda water for the first time, said, it tastes like my foot's asleep (92). 
At the far end of the spectrum, where the stimuli controlling a single response are genuinely different, we have a case of homonymy.

The complementary case of different responses being under the control of a single stimulus represents a case of synonymy, or the behavioral surrogate for synonymy, since the identity resides not in an abstract realm of meaning but in the sameness of the physical conditions defining the stimulus. The synonymy is partial if the stimuli in whose presence the different responses are emitted are similar but not identical. Here, too, a continuum of intermediate cases is found.

Mention of synonymy of course brings to mind the much contested question of the analyticsynthetic distinction, for one famous line of defense of the distinction seeks to define analytic sentences as ones in the case of which substitution of synonyms for synonyms turns such a statement into a trivial logical truth or a trivial statement of identity. Quine's equally famous objection to this defense is to point out that the definition of "synonymous" requires, in turn, the notion of "is analytic" (Quine 1951). One would expect a behaviorist to be skeptical of a principled analyticsynthetic distinction. Do we have here, instead, a free-standing, non-question-begging behavioral definition of synonymy, hence a non-circular definition of analyticity, and, thus, an unexpected, Skinnerian defense of the analytic-synthetic distinction ${ }^{19}$

Skinner, himself, touches upon the question of the analytic-synthetic distinction very near the end of the aforementioned section on "The Problem of Reference," and he there suggests a very different behavioral surrogate for analyticity. Skinner remarks that one might be tempted to map the analytic-synthetic distinction onto the distinction between the two classes of verbal operants, the intraverbals and the tacts. Intraverbals were mentioned above. Their distinguishing feature, as the 
name is meant to convey, is that the stimuli are, themselves, instances of verbal behavior, and there is no point-by-point correspondence between stimulus and response, as there is in, say, echoic behavior. Intraverbals come in many forms, including "chaining," "word association," and "translation."

Most relevant to the question of the analytic-synthetic distinction are intraverbal operants such as emitting the response four to the verbal stimulus two plus two, or the response unmarried male to the stimulus bachelor. One might have thought that one says two plus two is four because the terms, "two plus two" and "four" both refer to the same number, or that one says a bachelor is an unmarried male because the terms "bachelor" and "unmarried male" refer to all and only the same individuals. All four of these terms are associated with verbal responses that are part of tacts. But Skinner's point is that in a more complicated verbal response like two plus two is four, the stronger stimulus control over the utterance four is most likely exerted not by the property of the stimulus conditions under which four was first reinforced, stimulus conditions almost surely absent in the typical circumstances under which the longer utterance is emitted, such as a classroom mathematics exercise, but, instead, by the prior utterance, two plus two. The point is that the response four has been separately condition both to sets of four things, like four fingers, and to a wide array of verbal stimuli, including the responses the Gospels and sides of a square. As Skinner explains later in Verbal Behavior, the sense of "certainty" attaching to utterances such as two plus two is four is nothing more than the felt strength of the verbal stimulus control, or, in other words, the felt high probability of the response, four, on the occasion of the stimulus, two plus two.

As should be obvious, however, the cases of two plus two is four and a bachelor is an 
unmarried male differ little, if at all, from a behavioral point of view, from cases of seemingly synthetic sentences such as "Caesar crossed the Rubicon.” In the long history of the community's verbal practices, there once was a time when the response Caesar was conditioned to the individual so named. But that time being long in the past, the response Caesar is today part of a tact, if at all, only with an image as the stimulus, and even then the far stronger stimulus control is in the form of verbal prompts, such as the Roman emperor assassinated by Brutus. In the verbal behavior of most speakers of English, the response, crossed the Rubicon is almost exclusively under the stimulus control of the verbal response, Caesar. From a behavioral point of view, such "analytic" and "synthetic" statements are much alike in point of functional relations among stimulus, response, and contingencies of reinforcement. As Skinner says, "although all analytic sentences may be intraverbal-and hence have no 'referents' in terms of the present relation-all synthetic statements are not necessarily tacts" (Skinner 1957, 129). For Skinner, there is a difference between control by verbal and non-verbal stimuli, hence between intraverbals and tacts. But verbal behavior being the complicated thing that it is, virtually every response is, simultaneously, part of more than one verbal operant, and the only relevant distinction is one of degree, specifically the strength its being conditioned to a verbal or non-verbal stimulus. ${ }^{20}$

A final point of considerable importance to Skinner with respect to the tact as the behavioral surrogate for reference is implicit in what has just been said about the analytic-synthetic distinction. It is that a behavioral analysis does not respect an a priori distinction between sentences and words or even one between words and their parts. For Skinner, the unit of analysis is, again, the verbal operant, which is a functional relationship among stimulus, response, and contingencies of 
reinforcement. From this point of view, a response can be as long as a whole sentence or as short as a fragment of a word. A sentence-length response, day is done, can be conditioned to the setting of the sun as can be the word-length response, sunset. Word fragments can be part of tacts. Skinner mentions the example of the initial $s p$ in spit, speak, and spew (one might add spark, spend, and spurt), all of which are under the partial control of stimuli that include the emission of something, and the terminal each in screech, preach, and teach, all of which are under the partial control of noises produced vocally. Obviously not every response beginning with $s p$ or ending with each shares these kinds of stimulus control - think of sparrow and reach. Nor would the partial operant autonomy of $s p$ and each mean that responses like speech are properly analyzed simply as composites, since clearly the it in spit is not part of a similarly autonomous functional unit, and the whole response speech is obviously under determinate stimulus control as part of a tact.

A complete analysis of an episode of verbal behavior would identify multiple verbal operants at the level of the sentence, the phrase, the word, and the syllable, no one such functional element uniquely suited to serve as a carrier of meaning. But a more traditional semantics demands a principled distinction: The word or the phrase refers, but it is the sentence that is the bearer of truth values. Words and phrases refer, but it is sentences that assert. Can such distinctions be reflected in a behavioral analysis.

Skinner's view of assertion involves another class of verbal operants, the autoclitics. The distinguishing feature of autoclitics is that the controlling stimuli are properties of other verbal operants. One such property might be the strength of a response, which is to say, the probability of its being emitted in given stimulus conditions. Think of the way one expresses doubt by rising 
inflection on a word or phrase whose applicability is in question. I see someone resembling my nephew, John, but the context might be one in which John is not expected, or my view might be partially obscured, and so I utter the name John with rising pitch. What I might think is uncertainty is, from a behavioral point of view, just a comparatively weak probability of response, and it is that weakness of the probability of responding that functions as the stimulus controlling the rising inflection.

In English the weight of assertion is born mainly by the forms of the verb "to be." Consider the first- and third-person present form, "is." Consider now two cases. In the first, I am not sure whether the person I see is my nephew. I utter John with rising inflection. Then I get a clearer view and I utter it IS John. For Skinner, is is mainly what he terms an assertive autoclitic.

Another property of verbal behavior that might figure in an accompanying assertive autoclitic is the nature of the verbal operant in question. Skinner writes:

If I know that someone has said wolf and nothing else, the response will be of very little use. The speaker may be calling for help, describing an animal at the zoo, reading a sign, repeating what he has heard, or completing the phrase Big, bad .... An autoclitic will sharpen the effect by indicating some of the sources of strength, as well as the degree of strength [in both stimulus control and strength of response]. The assertive autoclitic has the specific function of indicating that the response is emitted as a tact or, under certain circumstances, as an interverbal. (Skinner 1957, 327)

From the operant point of view, assertion has nothing to do with the linguist's distinction between word and sentence. The assertive autoclitic is but another, distinctive pattern of functional relations among stimulus, response, and contingencies of reinforcement. The word-sentence distinction is irrelevant. Again, Skinner speaks directly to the philosopher's worry:

It is sometimes said that the word is inanimate but that language comes to life in the sentence. Words by themselves say nothing; it is the sentence which asserts. This is not the 
present distinction. (Skinner 1957, 327)

What, then, of truth? In traditional philosophical semantics, the reference of words undergirds the truth of the sentences composed with those words. "Caesar crossed the Rubicon" is true because "Caeser" refers to Caeser, "the Rubicon" refers to the Rubicon, and Caeser passed over the Rubicon in the manner indicated by the verb "crossed." For Skinner, the semantic notion of truth is replaced by the strength of the correlation between stimulus and response in the tact. In an operant analysis of verbal behavior, the only resources are the functional relations among stimulus, response, and contingencies of reinforcement. Of those, the strength of the correlation between stimulus and response in the tact is the best surrogate for the semantic notion of truth.

Verbal behavior is, by definition, social in the sense that the reinforcement of verbal responses is socially mediated. The speaker is, perforce, a member of a verbal community. Over a broad range of circumstances, it makes obvious good sense for the community to maintain contingencies of reinforcement that maximize the correlation between stimulus and response in the tact, which is to say, the differential strength of the stimulus control and the probability of response. Everything from mundane, day-to-day community life up to the long-term survival of the community are facilitated by predictable and reliable regularity in a speaker's responding verbally the same way to the same stimulus over a wide variety of circumstances.

The key to maintaining such strong correlations is generalized reinforcement. The community reinforces the response lion always and only when the speaker is in the presence of a lion or such evidence of a lion's presence as a roar, a scent, or a certain kind of movement in the grass. Background conditions are allowed to vary as are the circumstances of the speaker. In Skinner's own 
words:

Generalized reinforcement is the key to successful practical and scientific discourse. It brings the speaker's behavior most narrowly under the control of the current environment and permits the listener to react to that behavior most successfully in lieu of direct contact with the environment. When the correspondence with a stimulating situation is sharply maintained, when the listener's inferences regarding the objective situation are most reliable, we call the response "objective," "valid," "true," or "correct. (Skinner 1957, 147)

But, as Skinner also notes, stimulus control is never perfect, nor is verbal behavior ever completely independent of the speaker's current circumstance. One can contrive contingencies that maximize stimulus control and minimize the effects of bias, inattention, and fatigue. Still, the functional correlation between stimulus and response that is the behavioral surrogate for truth is never perfect and always a matter of degree.

Truth as strength of correlation between stimulus and response in the tact is the best behavioral surrogate for the semantic notion of truth. Truth as correlation between stimulus and response might seem like truth as correspondence, but the two differ for the same reasons that tacting is a replacement for, not an explication of, referring: A word is not a response and a tact is a threeterm functional relationship among stimulus, response, and contingencies of reinforcement, whereas truth is a two-term relationship between statement and fact. And, as with reference, so, too, with truth: The contingencies of reinforcement make all the difference, since it is the generalized nature of the reinforcement that ensures the strong nature of the correlation between stimulus and response.

\section{Further Consequences of the Tact as a Behavioral Surrogate for Reference}

Causal theories of reference were discussed, above, as a form of naturalism about reference. In them, an originary naming or dubbing or anointing - "This is Caesar" - fixes reference once and 
for all and always. How does an operant naturalism compare? Skinner discusses this very question, though not as a point about a causal theory of reference:

When we say that the word Caesar refers to Caesar, dead though he has been these thousand years, we are clearly not talking about the behavior of a contemporary speaker. A response of this form is almost certainly intraverbal, if it is not textual or echoic. A process of educational reinforcement has brought it under the control of various sets of verbal circumstances. Theoretically we should be able to trace these circumstances back to an instant in which a response was made to Caesar the man. The study of history assumes valid chains of this sort, and a predilection for primary sources is essentially the avoidance of unduly long, and hence probably faulty, chains. But the verbal behavior of the modern historian is still mostly intraverbal. (Skinner 1957, 128-129)

For Skinner, the essential point is not a causal relationship between Caesar and Caesar in an originary act of naming, but rather the controlling contingencies of reinforcement both back then and now. Back then what was crucial was the strength of the correlation between Caesar as stimulus and Caesar as response. Causality was involved, to be sure, but even then the causal chains were long and complicated, and the details of those causal chains were ultimately irrelevant to the brute fact of the strong stimulus control of Caesar on Caesar. But today the relevant contingencies are purely intraverbal (or textual or echoic). The reinforcing practices of ancestral verbal communities are relevant to understanding the genealogy of the reinforcing practices of contemporary verbal communities. But what matters most today is the status of Caesar as an intraverbal. There is, then, a kernel of truth in the causal theory of reference, judged from the point of view of an operant analysis. But it is only that operant analysis that makes clear when, where, and how the causal connection between Caesar and Caesar was once minimally relevant, and that same operant analysis exhibits the vastly diminished relevance of that causal connection for appreciating the behavioral semantics of Caesar today. 
What does an operant analysis of verbal behavior teach us about what Quine once termed the “vagaries of reference”(Quine 1960, 125): vagueness, ambiguity, referential opacity, and referential inscrutability? Vagueness and ambiguity are straightforwardly transcribed into questions about varieties of indefiniteness in the controlling stimuli in the tact. Referential inscrutability is more interesting. It is the analogue for referring terms of the indeterminacy of radical translation with respect to sentences. Just as behavioral evidence in the form of dispositions to assent to and dissent from queries systematically underdetermines our translation of "Gavagai” as "Rabbit” (or, as Quine notes, "Lo, a rabbit" - sentences are the unit of analysis), "Undetached rabbit part" or "Temporal slice of a rabbit," so too the behavioral evidence underdetermines the reference of the term "gavagai," leaving rabbits, undetached rabbit parts, and temporal slices of rabbits as equally serviceable candidates.

The surrogate question for Skinner would have to be one about the controlling variables in tacts comprising gavagai as the response among members of the native verbal community and the relationships of those functional patterns to the controlling variables in corresponding tacts among the members of the linguist's verbal community, including those that comprise the responses rabbit, undetached rabbit part, and temporal slice of a rabbit. The operant surrogate for the thesis of referential inscrutability would then be simply the mundane fact that the controlling stimulus in each of those tacts could equally well be described physically as rabbit, undetached rabbit part, or temporal slice of a rabbit, and, conversely, that each of the three responses - rabbit, undetached rabbit part, and temporal slice of a rabbit - could equally well be conditioned to those stimuli thus described. What was a surprising and provocative thesis about reference when first propounded by 
Quine becomes a triviality within an operant analysis of verbal behavior.

But an operant analysis also affords tools for understanding why the thesis of referential inscrutability (and translational indeterminacy) is so surprising. It is because, from an operant point of view, all of those responses - rabbit, undetached rabbit part, and temporal slice of a rabbit - also figure in a wide array of other verbal operants, including mands, intraverbals, textuals, echoics, and others, and it is in the functional relationships defining those other operants where the obvious and salient differences among rabbit, undetached rabbit part, and temporal slice of a rabbit are to be found. They are different responses, but the differences are largely irrelevant to their status within the crucial tacts, hence irrelevant from the point of view of the behavioral surrogate for reference.

Step back, now, from the immediate context of theories of reference to other contexts in which one wants to deploy a theory of reference. There are many such, but focus now only on epistemology and philosophy of science. If we think that knowledge is expressed in language, then an operant analysis of verbal behavior should make a difference in the way we theorize knowledge. As it happens, an operant analysis promises significant advantages on many fronts. Consider for now just these two, both of which concern areas of significant activity in the recent literature.

Philosophers of experiment argue that the philosopher of science's traditional emphasis on theory neglected the cognitive content that lives in experimental practice (see, for example, Franklin 1986). But the puzzle has always been how to understand especially the kind of non-discursive knowledge that is so much a part of experimental practice. To call it tacit knowledge is just to invent a name for our puzzlement. The operant approach gives us an answer. Since the experimental practices in question most definitely comprise behaviors whose governing contingencies are socially 
mediated, then such practices represent verbal behavior in exactly the same way in which discursive or vocal or textual behaviors do. In the domain of experimental practice, one will even find examples of intraverbals - manual verbal responses under the stimulus control of other manual verbal responses - echoics, and mands. Some crucial aspects of experimental practice will, of course, be non-verbal, the reinforcement coming from nature itself. But in many important ways experimental practice will prove to be just as verbal as publishing in the journals and speaking at professional meetings. From a operant point of view, the continuities between theory and experimental practice are many and obvious.

Social epistemology is another area of major interest in the contemporary epistemology and philosophy of science literature (see, for example, Goldman 1999, Longino 1990, and Solomon 2001). Here the puzzle has been to understand how knowledge can live in a community rather than in the mind of an individual. Dewey long ago pointed a way to an answer with his attack on Cartesian solipsism in The Quest for Certainty (Dewey 1929). But while Dewey's psychology was as resolutely social as Skinner's, it lacked the latter's technical sophistication about verbal behavior. As we have seen, Skinner defines verbal behavior precisely as behavior in which the contingencies of reinforcement are socially mediated. It follows that an epistemology constructed on this foundation will be social by definition. The burden of puzzlement will be reversed. The puzzle will be to understand how inherently social epistemic behaviors can (mistakenly?) be thought to reside in the minds of individual knowers. The solution to that puzzle has, however, also been suggested by Skinner with the above-mentioned notion of "sub-vocal verbal behavior." The idea is that vocal responses can be so attenuated as to be inaudible, even to the speaker, and yet still be controlled by 

is, thus, just a curiously private way of speaking about objects. Even the Cogito comes to be seen as a socially maintained response to a complicated set of verbal and non-verbal stimuli.

\section{Conclusion: Didn't Chomsky Prove Skinner Just Plain Wrong?}

It was said above that one of the reasons for contemporary neglect of Skinner's operant approach to verbal behavior is the legend of Chomsky's having killed the project with his famous review of Verbal Behavior (Chomsky 1959). Chomsky objects to many of Skinner's ideas, faulting the clarity even of the basic notions of stimulus, response, and reinforcement. His objections on these points are unsubtle, unsympathetic, and, in some instances, simply uninformed. Remarkably, he accuses Skinner of simply adopting wholesale the traditional semantics of reference. But one charge proved especially damning. Chomsky argued that Skinner's operant analysis of verbal behavior was, in principle, incapable of explaining the adult speaker's well-documented competence in recognizing the grammaticality of sentences wholly new to the speaker:

These are very remarkable abilities. We constantly read and hear new sequences of words, recognize them as sentences, and understand them. It is easy to show that the new events that we accept and understand as sentences are not related to those with which we are familiar by any simple notion of formal (or semantic or statistical) similarity or identity of grammatical frame. Talk of generalization in this case is entirely pointless and empty. It appears that we recognize a new item as a sentence not because it matches some familiar item in any simple way, but because it is generated by the grammar that each individual has somehow and in some form internalized. And we understand a new sentence, in part, because we are somehow capable of determining the process by which this sentence is derived in this grammar. (Chomsky 1959, 56)

Readers familiar with Chomsky's own then evolving project of transformational grammar (see, for example, Chomsky 1957), would get the point, a famous one from Chomsky, that only the posit of 
a universal and internalized grammatical competence can explain the speaker's capacity for recognizing the well-formedness of novel sentences. But readers familiar with Skinner's Verbal Behavior will see at once the question-begging nature of the charge. For precisely this point - the speaker's ability to respond to novel sentences as conforming to rules of grammar - is discussed by Skinner at length in Chapter 13, “Grammar and Syntax as Autoclitic Processes” (Skinner 1957, 331$343)$.

Chomsky discusses this chapter, but dismisses Skinner's approach to grammar with the following glib remark:

It is evident that more is involved in sentence structure than insertion of lexical items in grammatical frames; no approach to language that fails to take these deeper processes into account can possibly achieve much success in accounting for actual linguistic behavior. (Chomsky 1959, 54).

The actual evidence for what is claimed to be "evident" is simply not provided. A detailed and persuasive rejoinder to Chomsky on this point was provided by Kenneth MacCorquodale (MacCorquodale 1970,94-95). The key point missed or, rather, dismissed by Chomsky is simply that elements of syntax become, themselves, controlling stimuli in the production of verbal behavior, and so grammatical verbal behavior is to be explained as are all other elements of verbal behavior. There is, simply, no demonstrated need to posit internalized grammatical rules. Here is how MacCorquodale makes the point:

In sum, the verbally competent person can discriminate a syntactic dimension in speech as a stimulus, and he can emit speech which has syntactic properties in the sense that a hearer can discriminate them. This does not prove in any way that some underlying theory governs both behaviors. A child learns both to walk and to discriminate walking. Nothing is gained by saying that therefore he has constructed a theory of walking which he uses in his perceptions and in his activities. So he may be conceived to learn to speak and to perceive speech, directly and without stopping to construct a theory or apply a rule. (MacCorquodale 
$1970,95)$

Chomsky's error is then much like that of other students of behavior who leap to the postulation of intervening variables - in this case an internalized structure of grammatical rules - without realizing that the contingencies of reinforcement can do that work instead.

It is ironic that Chomsky faults Skinner for a failure to explain novelty in verbal behavior, because novelty was one of Skinner's main concerns. It helps to recall that the young Skinner wanted more than anything else to be a poet, even to the extent of trying out the poet's life in Greenwich Village (Skinner 1976). Skinner loved language and had a remarkable ear and eye for its complexity, subtlety, and nuance. Creativity is central. Among the most rewarding and impressive sections of Verbal Behavior are those devoted to mapping and explaining novelty in the form of metaphorical extension, stimulus generalization, and response induction. Miss that feature of the program and one misses what was most important to Skinner.

What, then, finally, of reference? As explained, what Skinner provides is not an explication of the traditional semantic notion of reference but a behavioral surrogate for it in the concept of the tact, a class of verbal operants distinguished by the strong control of non-verbal stimuli. As part of Skinner's larger operant analysis of verbal behavior, the tact affords the most sophisticated version of semantic naturalism on offer in the literature. It should be seen as the legacy of Dewey and the more fully formed behavioral semantics toward which Quine was reaching.

\section{Notes}

1. Rorty 1967, Hatfield 1990, Coffa 1991, Kusch 1995, Friedman 2000, and Heidelberger 2004 all provide helpful perspectives on aspects of this history. 
2. Of course one does not want to forget the central role that evolutionary naturalism played in the role of a continental thinker like Ernst Mach, whose "biologico-economical" point of view in epistemology owed a large debt to Darwin. Banks 2003 is a helpful recent study.

3. Dewey 1910, 1925 and Sellars 1922 are representative.

4. Donald Campbell is the best known early champion of the newer evolutionary epistemology; see, for example, Cambell 1974. See also the essays collected in Shimony and Nails 1987 for a broader perspective and Bradie 2008 for a briefer overview.

5. See Dewey 1922 and Quine 1969a, 1973.

6. Quine 1960 and 1968 are the main sources for the well-known Quinean theses of translational indeterminacy and referential inscrutabilitiy.

7. Another and related motivation among proponents of the causal theory of reference was that of providing a realist response to the kind meaning dependence and meaning change arguments that were advanced by Thomas Kuhn (1962) and others on behalf of one or another incommensurability thesis. For a discussion, see, for example, Rorty 1976. Yet another motivation, this especially for Kripke, was to fix flaws in Bertrand Russell's descriptive view of reference, according to which referring expressions are to be read as disguised definite descriptions. As Kripke pointed out, we succeed in referring uniquely even if, for example, we know of no unique definite description or when the definite descriptions we employ are false.

8. But even reference in this purely formal sense is implicated by another of Quine's famous arguments, this for "ontological relativity" (Quine 1968). According to Quine, ontology, hence reference, too, is relative both to the choice of the "background" language in terms of which the model is described and, obviously, to the way in which the mapping is constructed.

9. The most influential American structuralist was Edward B. Titchener at Cornell; see, for example, Titchener 1896. Functionalism was prominently advocated by Dewey's University of Michigan student and, later, University of Chicago colleague, James R. Angell; see Angell 1906. Hothersall 2004, 139-174, 361-392 provides a helpful overview of the history.

10. It would not be wrong to see here, ironcially, a vestige of the phenomenalism that dominated right-wing logical empiricism, a view that Quine otherwise famously disputed.

11. Chapter 3 of Word \& Object, "The Ontogenesis of Reference" (Quine 1960, 80-124), begins with a mention of Skinner's notion of operant behavior and cites Verbal Behavior, but mainly only for the general notion of the operant and even that is not deployed systematically in what follows.

12. See Katz and Fodor 1963, Katz 1972, and Fodor 1975. 
13. I am not the only one who thinks that the Chomsky review missed its mark; see, for example, MacCorquodale 1970. After developing some of Skinner's basic technical apparatus below, I will briefly explain what Chomsky got wrong.

14. See Watson 1930. The term "respondent" is Skinner's invention; see Skinner 1938, 20.

15. Appreciate the import of the fact that Skinner's reservations about intervening variables concerned mainly (a) the way they are poorly modeled by adventitiously available analogues in other sciences, (b) their, thereby, taking on a spurious reality, and (c) their inaccessibility to experimental control. What one should realize, then, is that his famous opposition to mentalism in psychology was not driven mainly by general philosophical, operationalist or positivist scruples about mind or the positing of unobservables. Instead, his worry was the perfectly respectable, scientific worry about the degree of experimental control one has over the details of one's theorizing. Obviously there are intervening variables. Obviously the accumulated experience of the organism inscribes itself somehow in some kind of central states. The problem is one's too quickly adverting to a handy model or some folk-psychological constructs in lieu of first doing the hard work of describing all of the experimentally accessible variables.

16. I say "primarily," because other independent variables, such as the organism's state of deprivation, might be relevant under certain circumstances.

17. I follow Skinner's own notational convention - italics and the exclamation mark - for designating the variety of operant, the "mand," further explained below, of which Water! is an instance.

18. A classic and influential discussion is found in Vygotsky 1934.

19. The notion of "stimulus synonymy" in Quine's work is related, but reflects Quine's making dispositions to assent and dissent from queries the chief form of behavioral evidence in translation. The sentence is Quine's basic unit of analysis. Stimulus synonymy of sentences, for Quine, is identity of "stimulus meaning" (Quine 1960, 46). He defines the stimulus meaning of a sentence as the ordered pair of the stimulus conditions under which a subject would assent to a sentence when queried and the stimulus conditions under which that subject would dissent to the sentence when queried (Quine 1960, 32-33). Whether Quine's notion of stimulus meaning and stimulus synonymy admits a straightforward translation into Skinner's theoretical vocabulary is not obvious, however much the two approaches share a behavioral orientation and a commitment to empiricism about language. But "bachelor" and "unmarried male" count as stimulus synonymous for Quine, just as bachelor and unmarried male count as synonymous for Skinner as responses conditioned to the same stimulus.

20. Compare Skinner's interpretation of analytic statements as intraverbals with Quine's notion of "stimulus analyticity." For Quine, a sentence is stimulus analytic if he would assent to it after every stimulation (Quine 1960, 55). Here, too, there is no direct translation from Quine's behavioral 
linguistics into Skinner's theory of verbal behavior, but both Skinner and Quine are pointing to a class of sentences or utterances that exhibit a specific kind of indifference to non-verbal stimuli, and for both, such a difference as there might be between such cases and those exhibiting greater dependence upon non-verbal stimuli is one of degree, not kind. 


\section{REFERENCES}

Angell, James R. (1904). Psychology: An Introductory Study of the Structure and Function of Human Consciousness. New York: Henry Holt.

Banks, Erik C. (2003). Ernst Mach's World Elements: A Study in Natural Philosophy. Dordrecht: Kluwer.

Boyd, Richard (1979). "Metaphor and Theory Change: What Is 'Metaphor' a Metaphor For?” In Metaphor and Thought. Andrew Ortony, ed. New York: Cambridge University Press, 481532.

Bradie, Michael (2008). "Evolutionary Epistemology.” In The Stanford Encyclopedia of Philosophy. Edward N.Zalta, ed. URL =<http://plato.stanford.edu/entries/epistemology-evolutionary/>.

Campbell, Donald T. (1974). "Evolutionary Epistemology." In The philosophy of Karl R. Popper. P. A. Schilpp, ed. LaSalle, IL: Open Court, 412-463.

Chomsky, Noam (1957). Syntactic Structures. The Hague: Mouton.

- (1959). Review of B. F. Skinner, Verbal Behavior. Language 35, 26-58.

Coffa, Alberto (1991). The Semantic Tradition from Kant to Carnap: To the Vienna Station. New York: Cambridge University Press.

Dewey, John (1896). “The Reflex Arc Concept in Psychology.” Psychological Review 3, 357-370. (1910). The Influence of Darwin on Philosophy and Other Essays in Contemporary Thought. New York: Henry Holt.

(1922). Human Nature and Conduct: An Introduction to Social Psychology. New York: Henry Holt and Co., 1922.

- (1925). Experience and Nature. Chicago and London: Open Court.

(1929). The Quest for Certainty: A Study of the Relation of Knowledge and Action. New York: Minton, Balch.

Fodor, Jerry A. (1975). The Language of Thought. Cambridge, MA: Harvard University Press. 
Franklin, Allan (1986). The Neglect of Experiment. Cambridge: Cambridge University Press.

Frege, Gottlob (1892). “Über Sinn und Bedeutung." Zeitschrift für Philosophie und philosophische Kritik 100, 25-50.

Friedman, Michael (2000). A Parting of the Ways: Carnap, Cassirer, and Heidegger. Chicago: Open Court.

Goldman, Alvin (1999). Knowledge in a Social World. Oxford: Oxford University Press.

Hatfield, Gary (1990). The Natural and the Normative: Theories of Spatial Perception from Kant to Helmholtz. Cambridge, MA : MIT Press.

- (2003). "Behaviourism and Naturalism." In The Cambridge History of Philosophy, 18701945. Thomas Baldwin, ed. Cambridge: Cambridge University Press, 640-48.

Heidelberger, Michael (2004). Nature from Within: Gustav Theodor Fechner and his Psychophysical Worldview. Cynthia Klohr, trans. Pittsburgh: University of Pittsburgh Press.

Hothersall, David (2004). History of Psychology, $4^{\text {th }}$ ed. New York: McGraw-Hill.

Jacquette, Dale, ed. (2003). Philosophy, Psychology, and Psychologism: Critical and Historical Readings on the Psychological Turn in Philosophy. Dordrecht: Kluwer.

Katz, Jerrold J. (1972). Semantic Theory. New York: Harper \& Row.

Katz, Jerrold J. and Jerry A. Fodor (1963). "The structure of a Semantic Theory." Language 39, $170-210$.

Kitcher, Philip (1992). “The Naturalists Return.” The Philosophical Review 101, 53-114.

Kripke, Saul (1971). "Identity and Necessity.” In Identity and Individuation. Milton K. Munitz, ed. New York: New York University Press, 135-164.

(1972). “Naming and Necessity.” In Semantics of Natural Language. Donald Davidson and Gilbert Harman, eds. Dordrecht: Reidel, 253-355. Reprinted as Naming and Necessity. Cambridge, MA: Harvard University Press, 1980.

Kuhn, Thomas S. (1962). The Structure of Scientific Revolutions. Chicago: University of Chicago Press.

Kusch, Martin (1995). Psychologism: A Case Study in the Sociology of Philosophical Knowledge. 
London and New York: Routledge.

Lee, Harold N. (1973). "Dewey and the Behavioral Theory of Meaning." Tulane Studies in Philosophy 22, 51-62.

Longino, Helen (1990). Science as Social Knowledge. Princeton: Princeton University Press.

MacCorquodale, Kenneth (1970). “On Chomsky’s Review of Skinner's Verbal Behavior.” Journal of the Experimental Analysis of Behavior 13, 83-99.

Neisser, Ulrich (1967). Cognitive Psychology. New York: Appleton-Century-Crofts.

Putnam, Hilary (1970). “Is Semantics Possible?” Metaphilosophy 1, 187-201. Revised version reprinted in Mind, Language, and Reality. Philosophical Papers, vol. 2. Cambridge: Cambridge University Press, 1975, 139-152.

Quine, W. V. O. (1951). “Two Dogmas of Empiricism'.” Philosophical Review 60: 20-43. Reprinted in: From a Logical Point of View. Cambridge, MA: Harvard University Press, 1953, 20-46.

(1960). Word \& Object. Cambridge: MIT Press.

(1968). "Ontological Relativity." The Journal of Philosophy 65, 185-212. Reprinted in Quine 1969b, 26-68.

(1969a). “Epistemology Naturalized.” In Quine 1969b, 69-90.

(1969b). Ontological Relativity and Other Essays. New York and London: Columbia University Press.

- (1973). The Roots of Reference. LaSalle, IL: Open Court.

Rorty, Richard (1967). The Linguistic Turn: Recent Essays in Philosophical Method. Chicago, University of Chicago Press.

_ (1976). “Realism and Reference.” The Monist 59, 321-337.

Ryle, Gilbert (1949). The Concept of Mind. London and New York: Hutchinson's University Library.

Sellars, Roy Wood (1922). Evolutionary Naturalism. Chicago and London: Open Court. 
Shimony, Abner and Debra Nails, eds. (1987). Naturalistic Epistemology: A Symposium of Two Decades. Dordrecht: Reidel.

Shook, John R. (2000). Dewey's Empirical Theory of Knowledge and Reality. Nashville, TN: Vanderbilt University Press.

Skinner, Burrhus Frederic (1938). The Behavior of Organisms: An Experimental Analysis. New York: Appleton-Century-Crofts.

— (1957). Verbal Behavior. New York: Appleton-Century-Crofts.

(1969). Contingencies of Reinforcement: A Theoretical Analysis. New York: AppletonCentury-Crofts.

(1976). Particulars of My Life: Part One of an Autobiography. New York: Knopf.

Solomon, Miriam (2001). Social Empiricism. Cambridge, MA: MIT Press.

Tarski, Alfred (1935). "Der Wahrheitsbegriff in den formalisierten Sprachen.” Studia Phiosophica 1, 261-405. English translation by J. H. Woodger: "The Concept of Truth in Formalized Languages.” In Logic, Semantics, Metamathematics: Papers from 1923 to 1938. Oxford: Clarendon, 152-278.

Titchener, Edward B. (1896). An Outline of Psychology. New York and London: Macmillan.

Vygotsky, Lev S. (1934). Myshlenie i rech'. Moscow: Gosudarstvennoe sotsial'no-ekonomicheskoe izdatel'stvo. English translation: Thought and Language. Eugenia Hanfmann and Gertrude Vakar, trans. Cambridge, MA: MIT Press, 1962.

Watson, John B. (1930). Behaviorism, rev. ed. Chicago: University of Chicago Press.

Wittgenstein, Ludwig (1922). Tractatus Logico-Philosophicus. London: Kegan Paul, Trench, and Trubner. 